\title{
ESTABELECIMENTO DE CRITÉRIOS PARA SELECIONAR PORTA-ENXERTOS DE MACIEIRA TOLERANTES AO ALUMÍNIO EM SOLUÇÃO NUTRITIVA ${ }^{1}$
}

\author{
ELAINE CRISTINA STOLF ${ }^{2}$, ADRIANA CIBELE DE MESQUITA DANTAS ${ }^{3}$, JOSÉ ITAMAR BONETI $^{4}$, \\ JUCINEI JOSÉ COMIN ${ }^{5}$, RUBENS ONOFRE NODARI ${ }^{6}$
}

RESUMO - Dentre todas as fruteiras de clima temperado, a macieira é a que mais atenção tem recebido no sentido de se obterem portaenxertos com características de boa adaptação, resistência ou sanidade. O desenvolvimento de um método eficiente para caracterizar genótipos com tolerância ao alumínio é o primeiro passo para a realização de estudos de mecanismos genéticos envolvidos na herança desse caráter. Assim, o presente trabalho teve por objetivo avaliar a tolerância ao alumínio dos porta-enxertos de macieira M.9 e Marubakaido em cinco concentrações $\left(0 ; 50 ; 150 ; 250\right.$ e $\left.350 \mu \mathrm{ML}^{-1}\right)$ em solução nutritiva. As estacas de Marubakaido, na concentração intermediária de alumínio apresentaram menor crescimento radicular e aéreo. O M.9 mostrou menor crescimento radicular nas concentrações de 250 e $350 \mu \mathrm{M}$ de alumínio. As características de crescimento avaliadas permitiram discriminar o porta-enxerto Marubakaido como mais tolerante que o M.9, e a concentração de $350 \mu \mathrm{M} \mathrm{L}^{-1}$ é a mais eficiente para a discriminação da tolerância ao alumínio aos 15 dias de cultivo em solução nutritiva.

Termos para indexação: Malus sp, melhoramento genético, tolerância ao alumínio.

\section{ESTABLISHMENT OF CRITERIA TO SELECT APPLE TREE ROOTSTOCKS TOLERANT TO THE ALUMINUM IN NUTRITIOUS SOLUTION}

\begin{abstract}
Among all of the temperate fruit trees, the apple tree is the one that has attracted more attention when it comes to obtaining rootstocks with characteristics of good adaptation, resistance or sanity. The development of an efficient method to characterize genotypes with tolerance to the aluminum is the first step for the accomplishment of genetic mechanisms studies involved in the inheritance of this character. Thus, the present work aimed to evaluate the tolerance to aluminum of the apple tree rootstocks M.9 and Marubakaido in five concentrations (0, 50, 150, 250 and $\left.350 \mu \mathrm{M} \mathrm{L}^{-1}\right)$ in nutritious solution. The cuttings of Marubakaido, in the intermediate concentration of aluminum presented smaller root and aerial growth. M.9 showed smaller root growth in the concentrations of 250 and $350 \mu \mathrm{M}$ of aluminum. The evaluated growth characteristics permitted to identify the apple rootstock Marubakaido as more tolerant than the M.9, and the concentration of $350 \mu \mathrm{M} \mathrm{L}^{-1}$ is the most efficient to identify the tolerance to aluminum in the 15 days of cultivation in nutritious solution. It is expected that later, this data can be used in works of individuals' selection in segregated populations accomplished in crossings with these two apple rootstocks.
\end{abstract}

Index Terms - Malus sp. genetic breeding, aluminum tolerance.

\section{INTRODUÇÃO}

A cultura da macieira possui papel de destaque no cenário frutícola brasileiro e mundial. Santa Catarina lidera a produção no País com a colheita de mais de meio milhão de toneladas ou quase dois terços das 844 mil toneladas de maçãs colhidas no País (ICEPA, 2005). Na região de São Joaquim, uma das principais regiões produtoras de Santa Catarina, vêm sendo realizados plantios principalmente com porta-enxertos Marubakaido (Malus prunifolia), utilizando como interenxerto M.9 (Malus pumila). Sobre esse sistema de produção de porta-enxerto, estão sendo enxertados nos clones Galaxy, Imperial Gala, Fuji Kiku e Fuji Suprema, e as variedades Catarina e Joaquina (Denardi, 2002). A utilização de 'M.9' como interenxerto sobre 'Marubakaido' está sendo amplamente usada no sistema de alta densidade, pois induz à redução do vigor das variedades-copa enxertadas, minimizando os problemas de produtividade. O porta-enxerto M.9 é de porte anão, apresenta resistência à podridão do colo e sensibilidade ao pulgão-lanígero, mas não possui boa adaptação a solos rasos e ácidos, característicos das regiões produtoras, em razão de ter sido selecionado para regiões de solos alcalinos da Europa (Boneti \& Katsurayama, 2001). O porta-enxerto Marubakaido, apesar de ser vigoroso, é suscetível a certas viroses, mas tem apresentado excelente comportamento em

${ }^{1}$ (Trabalho 134-07). Recebido em 22-05-2007. Aceito para publicação em : 04-01-2008.

${ }^{2}$ Eng. Agrônoma, Bolsista PIBIC-CNPq, Cetro de Ciências Agrárias, UFSC, C.P. 476, CEP. 88040-900, Florianópolis - SC, e-mail: ecstolf@yahoo.com.br ${ }^{3}$ Eng. Agrônoma, Dr., Prof. Adjunto, Universidade Estadual do Rio Grande do Sul, Polo de Bento Gonçalves, Benjamin Constant, 229, CEP: 95.700-000, Bento Gonçalves, RS, e-mail: adriana-dantas@uergs.edu.br

${ }^{4}$ Eng. Agrônomo, M. Sc., Pesquisador E.E. São Joaquim, Epagri, C.P. 81, 88600-000, São Joaquim - SC, e-mail: boneti@epagri.rct-sc.br

${ }^{5}$ Eng. Agrônomo, Dr., Professor Dep. Solos, Centro de Ciências Agrárias, UFSC, C.P. 476, CEP. 88040-900, Florianópolis - SC, e-mail: jcomin@eca.ufsc.br ${ }^{6}$ Eng. Agrônomo, Dr., Prof. Titular da Universidade Federal de Santa Catarina, Programa de Pós-graduação em Recursos Genéticos Vegetais, C.P. 476, CEP. 88040-900, Florianópolis - SC, Brasil., e-mail: nodari@cca.ufsc.br.

Rev. Bras. Frutic., Jaboticabal - SP, v. 30, n. 2, p. 476-481, Junho 2008 
situações de replantio em solos com baixa fertilidade, demonstrando boa capacidade de excluir o manganês e absorver melhor o cálcio, além de ser tolerante ao alumínio tóxico no solo (Bessho et al., 1993).

No Brasil, os viveiros e os pomares de macieira estão localizados em regiões nas quais os fatores edafoclimáticos são notadamente diferenciados daqueles que ocorrem nas demais regiões de cultivo ao redor do mundo. Os solos das regiões produtoras de maçã, no Sul do Brasil, apresentam $\mathrm{pH}$ muito baixo, e por isso o alumínio é solubilizado e ocorre um aumento da proporção de íons fitotóxicos deste elemento na solução do solo (Samac \& Tesfaye, 2003). A maioria das características de importância para o melhoramento de porta-enxertos tem controle poligênico, mas poucos são os trabalhos relacionados com a herdabilidade de resistência ao alumínio (Denardi, 2002). A seleção de um porta-enxerto clonal que apresente tolerância a altos níveis de alumínio no solo, proporcionaria menor custo de produção com aplicações de calcário e melhor aproveitamento de áreas atualmente não-cultivadas. Em muitas espécies cultivadas, uma série de mecanismos de tolerância ao alumínio têm sido identificados e selecionados para utilização em programas de melhoramento para a seleção de variedades tolerantes (Samak \& Tesfaye, 2003). Para os programas de melhoramento genético, é importante determinar critérios apropriados e objetivos que diferenciem o comportamento de genótipos tolerantes e suscetíveís a esta característica, garantindo, assim, o sucesso na seleção de genótipos que apresentem melhor performance em solos ácidos. Assim, o presente trabalho teve por objetivo determinar o efeito de diferentes concentrações de alumínio em solução nutritiva, em dois porta-enxertos de macieira, com vistas a estabelecer critérios de seleção em população segregante.

\section{MATERIAL E MÉTODOS}

Estacas dormentes foram retiradas em julho de 2005, na Estação Experimental de São Joaquim, Epagri-SC, dos portaenxertos de macieira Marubakaido e M.9. As mesmas foram cortadas em $15 \mathrm{~cm}$ de comprimento e foram imersas durante 10 segundos em solução contendo 2.000 ppm de ácido indolbutirico (AIB) na forma líquida. Em seguida, foram acondicionadas em bandejas contendo areia lavada e levadas para estufa de nebulização intermitente, onde permaneceram por 60 dias para o enraizamento. Posteriormente, foram selecionadas as estacas enraizadas quanto à uniformidade de tamanho de raízes, com 10 $\mathrm{cm}$ de comprimento para Marubakaido e $6 \mathrm{~cm}$ para M.9. Estas foram transferidas para vasos de polietileno, com capacidade para oito litros, com a solução nutritiva: $0,25 \mathrm{mM} \mathrm{KH}_{2} \mathrm{PO}_{4} ; 0,5$ $\mathrm{mMCa}\left(\mathrm{NO}_{3}\right)_{2} ; 0,5 \mathrm{mM} \mathrm{KNO}_{3} ; 0,5 \mathrm{mM} \mathrm{MgSO}_{4} ; 0,5 \mathrm{mM} \mathrm{NH}_{4} \mathrm{NO}_{3}$; $75 \mu \mathrm{M}$ Fe EDTA; $46 \mu \mathrm{M} \mathrm{B} ; 9 \mu \mathrm{M} \mathrm{Mn} ; 0,8 \mu \mathrm{M} \mathrm{Zn} ; 0,3 \mu \mathrm{M} \mathrm{Cu}$ e $0,05 \mu \mathrm{M}$ Mo (Edwards et al., 1976), livre de alumínio. A solução foi mantida sob agitação constante, com $\mathrm{pH}$ ajustado e mantido em 5,6 $\pm 0,2$. Após uma semana, foi realizada uma primeira avaliação do comprimento radicular e aéreo, denominada primeira leitura (PL), utilizando-se de uma régua milimétrica. Em seguida, as estacas foram transferidas para vasos contendo a mesma solução nutritiva descrita anteriormente, suplementada com diferentes concentrações de alumínio $\left(\mathrm{Al}^{3+}\right): 0 ; 50 ; 150 ; 250$ e $350 \mu \mathrm{M}$ adicionado na forma de $\mathrm{AlCl}_{3} .2 \mathrm{H}_{2} \mathrm{O}$. A partir daí, o $\mathrm{pH}$ das soluções foi mantido a $4,1 \pm 0,1$, e ajustado diariamente com $\mathrm{HCl} 1 \mathrm{~N}$. As soluções foram continuamente arejadas e trocadas a cada cinco dias. Os porta-enxertos foram mantidas em sala de crescimento, sob temperatura de $24 \pm 1^{\circ} \mathrm{C}$, fotoperíodo de 16 horas e U.R. entre $60-70 \%$, sob controle de termostato. $\mathrm{O}$ aumento do comprimento radicular e da parte aérea foi avaliado a cada 5 dias, até o $20^{\circ}$ dia, quando se procedeu a última leitura, denominada de leitura final (LF). Para a maioria dos autores, esse período de avaliação é suficiente para discriminar os diferentes genótipos. Foi determinada a diferença no comprimento radicular e na parte aérea (PL $-\mathrm{LF})$, bem como a percentagem de amarelecimento das folhas entre as diferentes concentrações de alumínio. Os dados foram obtidos a partir da área da folha amarelecida. O delineamento estatístico utilizado foi o inteiramente casualizado, constituído por cinco tratamentos, com 10 repetições por porta-enxerto, com três estacas cada repetição. Os dados foram submetidos à análise de variância, e as médias, comparadas pelo teste de SNK, a 5\% de probabilidade (Sokal \& Rohlf, 1988).

\section{RESULTADOS E DISCUSSÃO}

\section{Crescimento radicular}

Nos primeiros cinco dias de exposição ao alumínio, não foi observado diferença estatística entre os porta-enxertos nas diferentes concentrações (Tabela 1). O ‘Marubakaido' apresentou variação no crescimento radicular nos diferentes tratamentos. Quando submetido às concentrações de 150 e $350 \mu \mathrm{M}$ de alumínio, durante 20 dias, apresentou comprimento radicular de 6,2 e $6,3 \mathrm{~cm}$, respectivamente, valores que não diferiam dos 7,4 $\mathrm{cm}$ da testemunha. Com $250 \mu \mathrm{M}$ de alumínio, as estacas apresentaram o menor comprimento radicular $(0,04 \mathrm{~cm})$ independentemente do tempo de exposição (Tabela 1).

Por outro lado, após 20 dias de exposição, as estacas do 'M.9' apresentaram um incremento no crescimento radicular até a concentração de $150 \mu \mathrm{M} \mathrm{Al}$, quando os valores atingiram 12,1 $\mathrm{cm}$. Nas concentrações mais elevadas de alumínio (250 e 350 $\mu \mathrm{M})$, o crescimento radicular foi quase nulo $(0,32 \mathrm{~cm})$ (Tabela 1$)$, demostrando sintomas de toxidez no 'M.9'. Este, além de apresentar menor crescimento radicular, apresentou raízes mais grossas, intumescidas nas extremidades, quebradiças e com coloração mais escura (Figura 1). Os sintomas de toxidez de alumínio observados neste trabalho assemelham-se àqueles relatados por Braccini et al. (1998) em cafeeiro e por Fraguas (1996) em videiras suscetíveis ao alumínio. Em experimento semelhante com porta-enxertos de Citrus, Magalhães (1987) verificou que concentrações intermediárias de alumínio provocaram influência positiva no desenvolvimento da parte aérea e radicular em plantas de limão "Rugoso FM". A aplicação de $0,5 \mathrm{mM}$ de alumínio em solução, por três semanas, incrementou a atividade radicular de plântulas de Melastoma malabathricum (Watanabe et al., 2005). Foy (1974) relata que espécies tolerantes parecem responder favoravelmente a adições moderadas de alumínio na solução. 
Os mecanismos de tolerância ao alumínio diferem de acordo com a espécie. Um dos parâmetros mais utilizados para a determinação da tolerância ou suscetibilidade é o desenvolvimento radicular, que está diretamente relacionado à atividade mitótica, em elevadas concentrações de alumínio (Samac $\&$ Testaye, 2003). Prazac (2001) sugere que os íons Al em determinadas concentrações podem alterar a distribuição de hormônios endógenos nas células radiculares e estimular a atividade mitótica no meristema apical da raiz. Eckert et al. (1996) verificaram que plantas de cevada (Hordeum vulgare L.) tolerantes e suscetíveis, expostas ao alumínio em solução nutritiva, também não apresentaram interação significativa entre as concentrações e cultivares. Tanto as plantas tolerantes quanto as suscetíveis apresentaram decréscimo na percentagem de divisão celular com o aumento da concentração de alumínio em solução, e só foi detectada diferença significativa entre as cultivares em solução contendo baixa concentração de alumínio. No entanto, esses mesmos autores verificaram que plantas tolerantes, mantidas em concentração tóxica de alumínio, ao serem transferidas para solução livre de alumínio, retomaram a taxa de divisão celular de maneira mais eficiente que as plantas suscetíveis.

\section{Parte aérea}

Após 20 dias de exposição ao Al, somente foram detectadas diferenças quanto ao comprimento da parte aérea no 'Marubakaido' (Tabela 2). As estacas de 'Marubakaido' apresentaram maior comprimento da parte aérea na concentração de $50 \mu \mathrm{M}$ de alumínio $(3,2 \mathrm{~cm})$, enquanto o menor comprimento foi observado com $250 \mu \mathrm{M}$ de alumínio $(0,2 \mathrm{~cm})$ (Tabela 2). Porém, com relação ao aumento no comprimento da parte aérea das estacas do 'M.9', as concentrações de alumínio não foram estatisticamente significativas (Tabela 2). De forma geral, observou-se que o crescimento da parte aérea do 'Marubakaido' foi maior nas diferentes concentrações de alumínio em relação ao 'M.9' (Figura 2).

Paszt \& Mercik (2004) verificaram que, em condições ácidas ( $\mathrm{pH} 3,6)$, as folhas, raízes e brotos dos porta-enxertos de macieira M.9 e M.26 acumularam quantidades excessivas de Al e $\mathrm{Mn}$, e apresentaram redução no diâmetro, no crescimento, no peso seco dos brotos e diminuição do número de flores e frutos. A redução do crescimento da parte aérea também foi observada por Dantas et al. (2001) nos porta-enxertos de macieira M.111 e M.9 cultivados em solução nutritiva contendo alumínio. O sítio principal da toxidez ao alumínio é o ápice da raiz (meristema) (Ryan et al., 1997), onde ocorre o maior acúmulo desse elemento, com uma pequena quantidade sendo translocada para a parte aérea da planta (Braccini et al., 1998), acumulando-se preferencialmente no ápice radicular. Kollmeier et al. (2000) verificaram que plantas de milho tratadas com alumínio apresentaram rápida inibição do fluxo de auxina, favorecendo o transporte acrópeto ao invés do basípeto. Esse efeito dá início à ação do alumínio na indução das alterações nas células radiculares, ocorrendo a inibição na divisão das células próximas e estímulo da divisão das células localizadas na zona mais distal (Doncheva et al., 2005).
Durante o cultivo das estacas de 'Marubakaido' e 'M.9', foram observadas diferentes percentagens de amarelecimento das folhas. As estacas cultivadas em solução com $250 \mu \mathrm{M} \mathrm{Al}$ apresentaram todas as folhas amareladas, diferindo significativamente $(\mathrm{P}>5 \%)$ dos tratamentos com 0 e $150 \mu \mathrm{M} \mathrm{Al}$ que apresentaram as menores percentagens de amarelecimento foliar (46,6 e 35,0\%, respectivamente) (Figura 3a). Também foi observado amarelecimento das folhas em 'M.9'. As estacas submetidas às maiores concentrações $(250$ e $350 \mu \mathrm{M} \mathrm{Al})$ apresentaram 100 e $97,3 \%$ de folhas amareladas, respectivamente, valores que diferiram significativamente do tratamento com 150 $\mu \mathrm{M} \mathrm{Al}(11,25 \%)$, que apresentou a menor média para essa característica (Figura $3 b$ ).

Em experimento de toxidez do alumínio em café, um dos efeitos indiretos do elemento na parte aérea foi o encurtamento dos internódios, resultando em menor altura e também em clorose foliar (Braccini et al., 1998). Em plântulas de Hordeum vulgare tratadas com alumínio $(0,5 \mathrm{mM})$, também foi verificado clorose (amarelecimento das folhas), o que pode estar associado ao decréscimo das concentrações N, P e K nas folhas (Watanabe et al., 2005). Em estudo realizado por Wojcik (2003), o índice de absorção e translocação de $\mathrm{P}, \mathrm{Mg}$ e Ca para a parte aérea de porta-enxerto de macieira P22 e M.26 decresceu quando cultivadas na presença de alumínio, reduzindo a produção de biomassa em 22 e $41 \%$, respectivamente. O excesso de alumínio na solução pode proporcionar a formação de complexos na superfície da raiz que precipitam como fosfato de alumínio, impedindo a absorção de $\mathrm{P}$ e, conseqüentemente, o desenvolvimento da parte aérea (Marschner, 1995).

\section{Tempo de exposição ao alumínio}

Houve diferenças significativas no crescimento radicular dos porta-enxertos Marubakaido e M.9 quanto ao tempo de exposição ao alumínio em cada tratamento. As estacas do 'Marubakaido'apresentaram crescimento significativo das raízes a partir dos 15 dias de cultivo quando submetidas a 0 e $350 \mu \mathrm{M}$ de alumínio. A diferença no crescimento radicular das estacas submetidas a $150 \mu \mathrm{M}$ só foi claramente observada aos 20 dias de cultivo, nos tratamentos que resultaram no menor crescimento da radícula. Entretanto, o desenvolvimento radicular até o final do cultivo permaneceu estável, sem apresentar diferenças significativas (Figura 4).

O 'M.9' apresentou crescimento mais lento quando comparado às estacas do 'Marubakaido', até os 15 dias. Só foi possível observar diferenças no crescimento aos 20 dias de cultivo nas concentrações de 50 e $150 \mu \mathrm{M}$ Al. Nos tratamentos contendo as maiores concentrações de alumínio, não houve crescimento radicular no período avaliado. Ao se comparar o efeito do tempo de cultivo entre os tratamentos e entre as cultivares, somente foram verificadas diferenças significativas nas concentrações 150 e $350 \mu \mathrm{M}$. O tratamento contendo 150 $\mu \mathrm{M} \mathrm{Al}$ favoreceu o crescimento radicular de ambos os portaenxertos, porém o porta-enxerto M.9 apresentou maior crescimento quando comparado ao 'Marubakaido', aos 20 dias de cultivo. Já, no tratamento contendo $350 \mu \mathrm{M} \mathrm{Al}$, o comportamento entre os porta-enxertos foi oposto: o 
'Marubakaido' apresentou crescimento radicular favorecido a partir de 10 dias de cultivo, enquanto o 'M.9' não apresentou crescimento ao longo do experimento (Figura 4). Portanto, neste trabalho, o tratamento contendo $350 \mu \mathrm{M}$ de alumínio foi mais eficiente para discriminar o porta-enxerto tolerante (Marubakaido) do suscetível (M.9), aos 15 dias de cultivo em solução nutritiva.

TABELA 1- Médias de diferença no comprimento radicular (cm) e crescimento relativo de estacas dos portaenxertos de macieira Marubakaido e M.9 submetidos a diferentes concentrações de alumínio em solução nutritiva, ao longo 20 dias.

\begin{tabular}{|c|c|c|c|c|c|}
\hline \multicolumn{6}{|c|}{ Crescimento radicular $(\mathbf{c m})$} \\
\hline \multirow{2}{*}{ Al (uM) } & \multicolumn{4}{|c|}{ Dias de exposição ao Al } & \multirow{2}{*}{$\begin{array}{l}\text { Crescimento } \\
\text { relativo (\%) }\end{array}$} \\
\hline & 5 & 10 & 15 & 20 & \\
\hline \multicolumn{6}{|l|}{ Marubakaido } \\
\hline $\mathbf{0}$ & $0,71 \mathrm{~A} \mathrm{a}$ & $3,20 \mathrm{AB} \mathrm{c}$ & $6,14 \mathrm{BC} \mathrm{b}$ & $7,39 \mathrm{C} \mathrm{b}$ & 38,81 \\
\hline 50 & $0,14 \mathrm{~A} \mathrm{a}$ & $0,33 \mathrm{~A} \mathrm{ab}$ & $1,09 \mathrm{~A} \mathrm{a}$ & $2,76 \mathrm{~A} \mathrm{ab}$ & 19,11 \\
\hline 150 & $0,22 \mathrm{~A} \mathrm{a}$ & $1,33 \mathrm{Ac}$ & $4,70 \mathrm{AB}$ a & $6,22 \mathrm{~B} \mathrm{~b}$ & 36,52 \\
\hline 250 & $0,04 \mathrm{~A} \mathrm{a}$ & $0,04 \mathrm{~A} \mathrm{a}$ & $0,04 \mathrm{~A} \mathrm{a}$ & $0,04 \mathrm{~A} \mathrm{a}$ & 0,37 \\
\hline 350 & $0,23 \mathrm{~A} \mathrm{a}$ & $1,04 \mathrm{~A} \mathrm{bc}$ & $3,71 \mathrm{~B} \mathrm{a}$ & $6,28 \mathrm{C} \mathrm{b}$ & 38,89 \\
\hline \multicolumn{6}{|l|}{ M.9 } \\
\hline $\mathbf{0}$ & $0,47 \mathrm{~A} \mathrm{a}$ & $1,75 \mathrm{~A} \mathrm{a}$ & $3,37 \mathrm{~A} \mathrm{ab}$ & $4,80 \mathrm{~A}$ ab & 23,84 \\
\hline 50 & $0,47 \mathrm{~A} \mathrm{a}$ & $0,47 \mathrm{~A} \mathrm{a}$ & $0,47 \mathrm{~A} \mathrm{a}$ & $4,35 \mathrm{~B} \mathrm{ab}$ & 43,13 \\
\hline 150 & $0,92 \mathrm{~A} \mathrm{a}$ & $5,00 \mathrm{AB} \mathrm{b}$ & $7,5 \mathrm{~B} \mathrm{~b}$ & $12,12 \mathrm{C} \mathrm{b}$ & 65,77 \\
\hline 250 & $0,10 \mathrm{~A} \mathrm{a}$ & $0,10 \mathrm{~A} \mathrm{a}$ & $0,20 \mathrm{~A} \mathrm{a}$ & $0,20 \mathrm{~A} \mathrm{a}$ & 0,96 \\
\hline 350 & $0,32 \mathrm{~A} \mathrm{a}$ & $0,32 \mathrm{~A} \mathrm{a}$ & $0,32 \mathrm{~A} \mathrm{a}$ & $0,32 \mathrm{~A} \mathrm{a}$ & 5,54 \\
\hline
\end{tabular}

Médias seguidas de mesma letra não diferem pelo teste SNK, ao nível de $5 \%$ de probabilidade. Letras maiúsculas comparam a diferença do crescimento radicular ao longo do tempo na mesma concentração (linha) e as letras minúsculas comparam a diferença do crescimento radicular entre concentrações (colunas).

TABELA 2 - Médias de diferença no comprimento aéreo de estacas dos porta-enxertos de Marubakaido e M.9 submetidos a diferentes concentrações de alumínio em solução nutritiva, ao longo 20 dias.

\begin{tabular}{ccccc}
\hline \multirow{2}{*}{ Al (uM) } & \multicolumn{5}{c}{ Dias de exposição ao Al } \\
\cline { 2 - 5 } & $\mathbf{5}$ & $\mathbf{1 0}$ & $\mathbf{1 5}$ & $\mathbf{2 0}$ \\
\hline Marubakaido & $0,20 \mathrm{~A} \mathrm{a}$ & $0,20 \mathrm{~A} \mathrm{a}$ & $0,55 \mathrm{~A} \mathrm{a}$ & $1,03 \mathrm{~A} \mathrm{ab}$ \\
$\mathbf{0}$ & $1,74 \mathrm{~A} \mathrm{a}$ & $1,74 \mathrm{~A} \mathrm{a}$ & $3,11 \mathrm{~A} \mathrm{a}$ & $3,19 \mathrm{~A} \mathrm{~b}$ \\
$\mathbf{5 0}$ & $0,16 \mathrm{~A} \mathrm{a}$ & $0,47 \mathrm{~A} \mathrm{a}$ & $0,71 \mathrm{~A} \mathrm{a}$ & $0,95 \mathrm{~A} \mathrm{ab}$ \\
$\mathbf{1 5 0}$ & $0,13 \mathrm{~A} \mathrm{a}$ & $0,23 \mathrm{~A} \mathrm{a}$ & $0,23 \mathrm{~A} \mathrm{a}$ & $0,23 \mathrm{~A} \mathrm{a}$ \\
$\mathbf{2 5 0}$ & $0,14 \mathrm{~A} \mathrm{a}$ & $0,43 \mathrm{AB} \mathrm{a}$ & $0,74 \mathrm{AB} \mathrm{a}$ & $0,89 \mathrm{~B} \mathrm{ab}$ \\
$\mathbf{3 5 0}$ & $0,00 \mathrm{~ns}$ & $0,00 \mathrm{~ns}$ & $0,00 \mathrm{~ns}$ & $0,05 \mathrm{~ns}$ \\
\hline $\mathbf{M} 9$ & $0,00 \mathrm{~ns}$ & $0,00 \mathrm{~ns}$ & $0,12 \mathrm{~ns}$ & $0,12 \mathrm{~ns}$ \\
$\mathbf{0}$ & $0,32 \mathrm{~ns}$ & $0,35 \mathrm{~ns}$ & $0,37 \mathrm{~ns}$ & $0,37 \mathrm{~ns}$ \\
$\mathbf{5 0}$ & $0,00 \mathrm{~ns}$ & $0,00 \mathrm{~ns}$ & $0,00 \mathrm{~ns}$ & $0,00 \mathrm{~ns}$ \\
$\mathbf{1 5 0}$ & $0,12 \mathrm{~ns}$ & $0,12 \mathrm{~ns}$ & $0,12 \mathrm{~ns}$ & $0,15 \mathrm{~ns}$ \\
$\mathbf{2 5 0}$ & $\mathbf{3 5 0}$ & &
\end{tabular}

Médias seguidas de mesma letra não diferem pelo teste SNK, ao nível de $5 \%$ de probabilidade. Letras maiúsculas comparam a diferença do crescimento radicular ao longo do tempo para a mesma concentração (linha) e as letras minúsculas comparam a diferença do crescimento radicular entre concentrações (coluna).
Este resultado é semelhante ao obtido por Malavolta et al. (1981) em que o uso de solução nutritiva com alta concentração de alumínio $(440 \mu \mathrm{M})$ permitiu boa discriminação entre híbridos de sorgo tolerantes e suscetíveis. Salvador et al. (2000) observaram em solução nutritiva que concentrações de $\mathrm{Al}^{3+}$ abaixo de 10 $\mathrm{mg} . \mathrm{L}^{-1}$ aumentaram a altura da planta e a área foliar em mudas de goiabeira (Psidium guajava L.), respectivamente, aos 30 e 90 dias de cultivo.

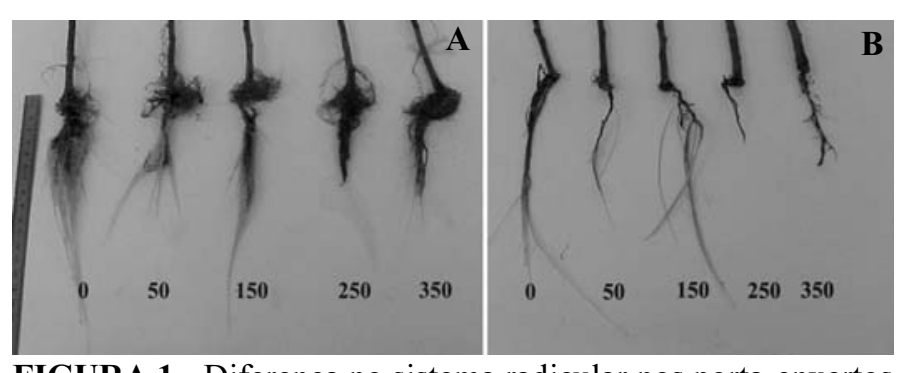

FIGURA 1 - Diferença no sistema radicular nos porta-enxertos Marubakaido (A) e M.9 (B) submetidos a diferentes concentrações de alumínio $(\mu \mathrm{M})$ em solução nutritiva, após 20 dias de tratamento.

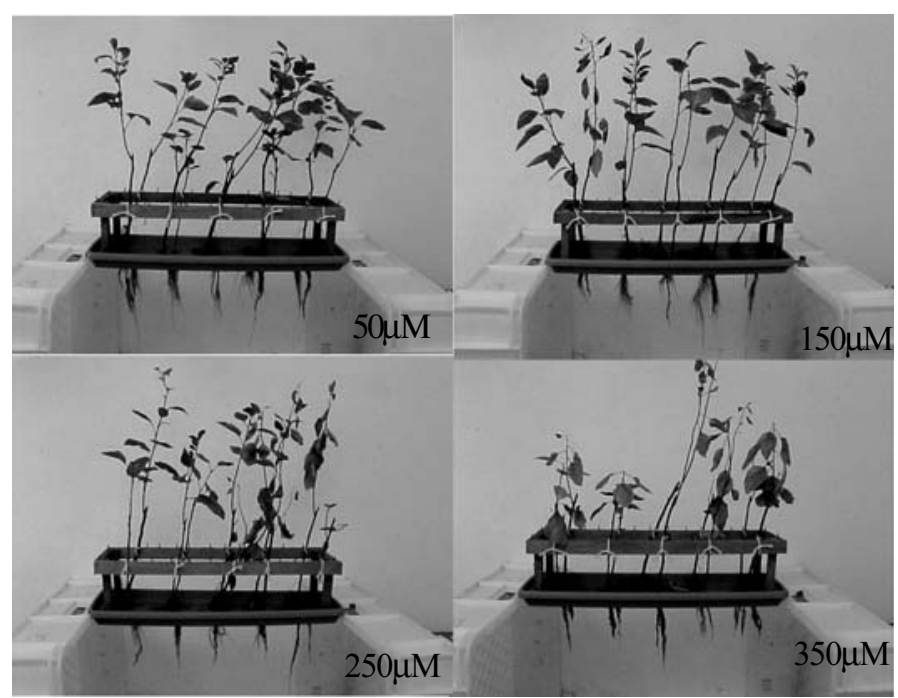

FIGURA 2 - Crescimento da parte aérea do porta-enxerto Marubakaido nas diferentes concentrações de alumínio. 

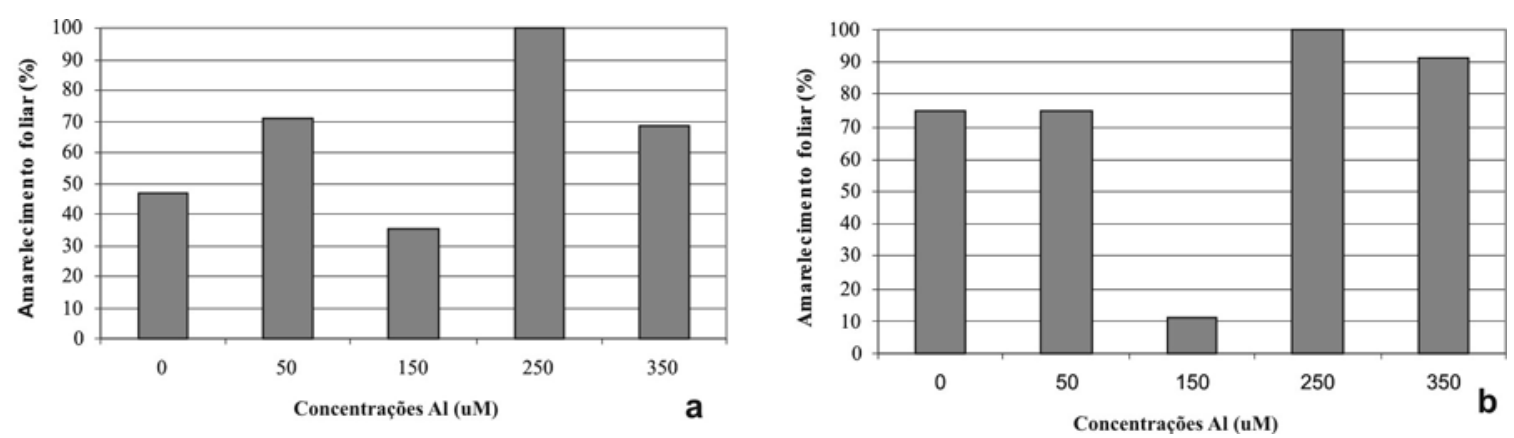

FIGURA 3 - Percentagem de amarelecimento foliar apresentado pelas estacas dos porta-enxertos Marubakaido (a) e M.9 (b) submetidos a diferentes concentrações de alumínio em solução nutritiva, ao longo 20 dias.
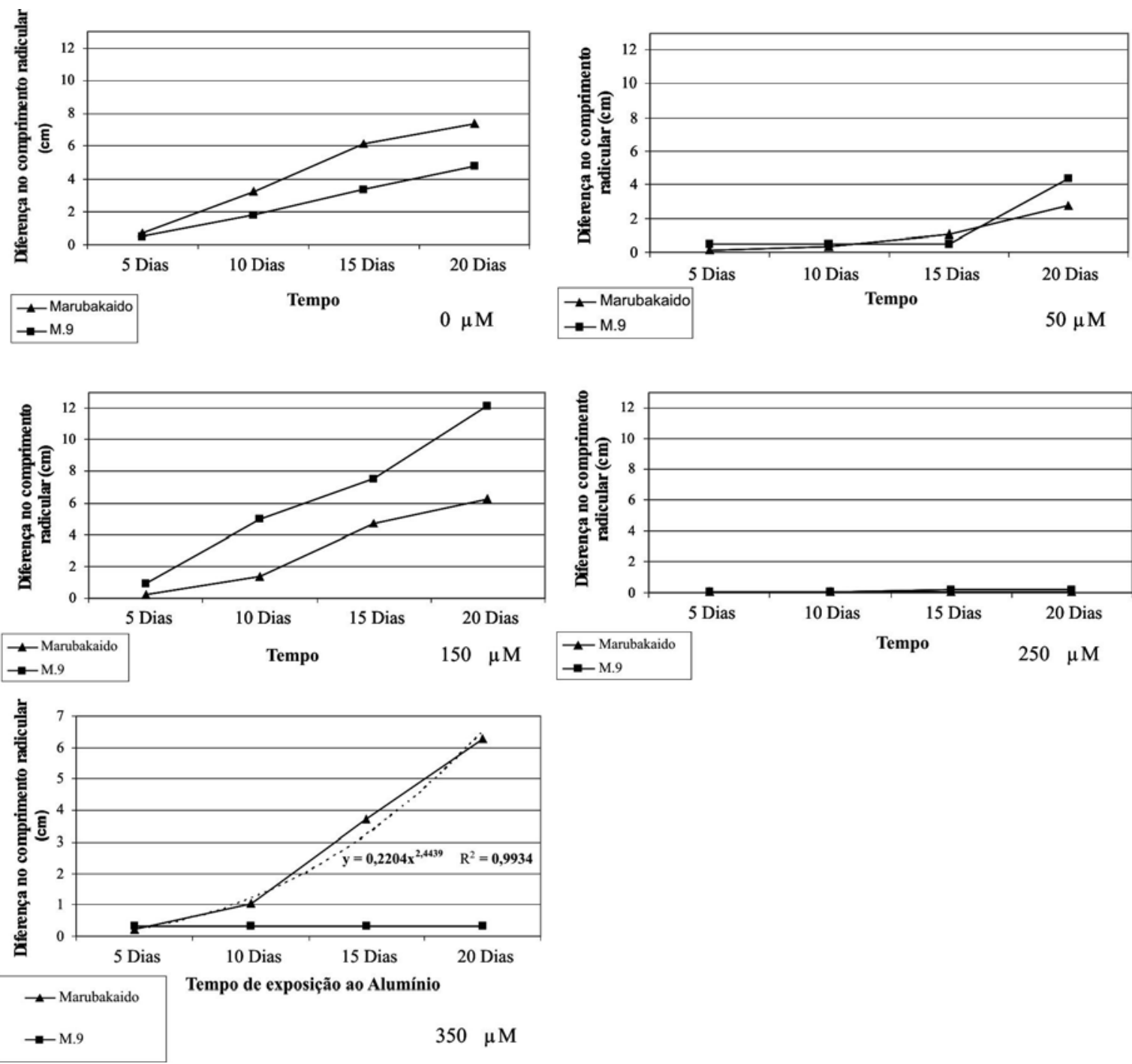

FIGURA 4 - Crescimento radicular de estacas do porta-enxerto de macieira tolerante (Marubakaido) e suscetível (M.9) ao alumínio, submetidos a diferentes concentrações de alumínio em solução nutritiva, ao longo 20 dias. 


\section{CONCLUSÕES}

1-A presença do alumínio inibiu o crescimento da parte aérea e das raízes, as quais apresentaram anormalidades morfológicas típicas da injúria provocada por esse elemento químico.

2-A característica de crescimento avaliada permitiu discriminar o porta-enxerto Marubakaido como mais tolerante que o M.9, sendo a concentração de $350 \mu \mathrm{M}$ Al considerada mais eficiente para a discriminação da tolerância ao alumínio em solução nutritiva, aos 15 dias de cultivo.

\section{REFERÊNCIAS}

BESSHO, H., SOEJIMA, J., ITO, Y., KOMORI, S. Breeding and genetic analysis of apple in Japan. In: HAYASHI, T., OMURA, M., SCOTT, N.S. Techniques on gene diagnosis and breeding in fruit trees. Tsukuba: Fruit Tree Research Station, 1993. p. 231240.

BRACCINI, M.C.L.; MARTINEZ, H.E.P.; PEREIRA, P.R.G.; SAMPAIO, N.F.; SILVA, E.A.M. Tolerância de genótipos de cafeeiro ao alumínio em solução nutritiva. I. Crescimento e desenvolvimento da parte aérea e sistema radicular. Revista Brasileira de Ciência do Solo, Campinas, v. 22, p. 435-442, 1998.

DANTAS,A.C.M.; FORTES, G.R.L.; SILVA, J.B.; NEZI, A.N.; RODRIGUES, A.C. Tolerância ao alumínio em porta-enxertos somaclonais de macieira cultivados em solução nutritiva. Pesquisa Agropecuária Brasileira, Brasília, v.36, n.4, p.615-623, 2001.

DENARDI, F. Porta-enxertos. In: EPAGRI. A cultura da macieira. Florianópolis, 2002 p. 169-227.

DONCHEVA, S.; AMENÓS, M.; POSCHENRIEDER, C.; BARCELÓ, J. Root cell patterning: a primary target for aluminum toxicity in maize. Journal Experimental Botany, Oxford, v.56, p.1213-1220, 2005.

EDWARDS, J.H.; HORTON, B.D.; KIRKPATRICK, H.C. Aluminum toxicity symptoms in peach seedlings. Journal American Society of Horticulture Science, Alexandria, v.101, p.139-142, 1976.

ECKERT, M.I.; VIEGAS, J.; OSORIO, E.A.; SILVA, J.B.; BRAUNER, J.L. Aluminum toxicity in barley (Hordeum vulgare L.) root tips. Brazilian Journal of Genetics, Ribeirão Preto, v.19, n.3, p.429-433, 1996.

FOY, C.D. Effects of aluminum in plant growth. In: CARSON, E.W. (Ed). The plant root and its environment. Chatottesville: University of Virginia, p. 601-642, 1974.
FRAGUAS, J.C. Sintomatologia da toxidez do alumínio em portaenxertos de videira. Bento Gonçalves: Embrapa-CNPUV, 1996. 20p. (Circular técnica, 20).

KOLLMEIER, M.; FELLE, H.; HORST, W.J. Genotypic differences in aluminum resistance of maize are expressed in the distal part $f$ the transition zone: is reduced basipetal auxin flow involved in inhibition of roots elongation by aluminum? Plant Physiology, Bethesda, v. 122, p.945-956, 2000.

MAGALHAES, A.F.J. Tolerancia de porta-enxertos de citrus ao alumínio. Revista Brasileira de Fruticultura, Jaboticabal, v. 9, n.3, p.51-55, 1987.

MALAVOLTA E., NOGUEIRA, F.D., PEREIRA I.O. Aluminum tolerance in sorghum and beans-methods and results. Journal of Plant Nutrition, New York, v.3, n. 1-4, p. 689-694, 1981.

MARSCHNER, H. Mineral nutrition of higher plants. $2^{\text {nd }} \mathrm{ed}$. London: Academic Press, 1995.

PASZT, L. S.; MERCIK, S. The response of apple rootstocks P22, M.9 and M.26, and apple tree cultivars 'Jonagold' and 'Gala' to soil acidification. Acta Horticulturae, Wageningen, v.636, p.167-172, 2004.

PRAZAC, R. Influence of aluminium from $\mathrm{AlCl}_{3}$ on differentiation and growth of Dendrobium kingianum Bidwill in in vitro conditions. Plant Nutrition, p.178-179, 2001.

SALVADOR, J.O. et al. Influencia do alumínio no crescimento e na acumulação de nutrientes em mudas de goiabeira. Revista Brasileira de Ciência do Solo, Campinas, v.24, p.787-796, 2000.

SAMAC, D.; TESFAYE, M. Plant improvement for tolerance to aluminum in acid soils - a review. Plant Cell, Tissue and Organ Culture, Dordrecht, v.75, p. 198-207, 2003.

RYAN, P.R.; SKERRETT, M.; FINDLAY, G.P.; DELHAIZE, E.; TYERMAN, S.D. Aluminum activates an anion channel in the apical cells of wheat roots. Proceedings National Academic Science, Melville, v.94, p.6547-6552, 1997.

WATANABE, T.; JANSEN, S.; OSAKI, M. The beneficial effect of aluminum and the role of citrate in $\mathrm{Al}$ accumulation in Melastoma malabathricum. New Physiologist, Inglaterra, v.165, p.773-780, 2005.

WOJCIK, P. Impact of boron on biomass production and nutrition aluminum-stressed apple rootstocks. Journal of Plant Nutrition, New York, v.26, n.12, p.2439-2451, 2003. 